\title{
Preventing And Detecting Plagiarism In The Written Work Of College Students
}

\author{
Jane Whitney Gibson, (E-mail: Gibson@ @uizenga.nova.edu), Nova Southeastern University \\ Charles W. Blackwell, Nova Southeastern University \\ Regina A Greenwood, Kettering University \\ Ingrid Mobley, College of the Bahamas \\ Raquel Whitney Blackwell, St. Leo University
}

\begin{abstract}
Plagiarism abounds on American college campuses. This paper first examines reasons that college students cheat, using both the perspective of student respondents and the observations of the faculty authors. Next, the paper examines the two strategies which can be taken to combat student plagiarism: prevention and detection. Specific strategies are offered for each approach.
\end{abstract}

\section{INTRODUCTION}

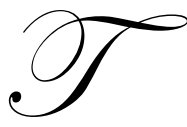

here has been an assortment of articles in the last few years on the problem of plagiarism among U.S. college students (Johnson, 2000; Scanlon, 2002; Born, 2003; Willen, 2004; Warger, 2005). As early as 1993, Goode cautioned:

Some say plagiarism, fraud, and other scholarly misconduct are spreading like wildfire over a dry and parched terrain, out of control. Others aren't sure what the extent of the problem is. But almost everyone agrees it has gotten worse on the nation's campuses. (para. 2)

Goode (1993) further reported that studies across the country showed that between $50-70 \%$ of college freshmen admit to some type of cheating. By 1993, one study cited the existence of at least 70 term paper mills including A-Plus Termpapers and Paperz.com. (Basinger \& McCollum, 1997). By 1999, the concern was so widespread that U.S. News \& World Reports had a cover which announced "a new epidemic of fraud is sweeping through our schools." (Scanlon, 2002, para 2) In 2001, a study by Donald McCabe reported that $41 \%$ of students admitted they engaged in "cutting and pasting" from online sources. (Sterngold, 2004) Surveys done in 2003 and 2004 of over 40,000 undergraduates on 68 campuses showed that $21 \%$ of respondents admitted to at least one serious incident of test or exam cheating while $51 \%$ admitted to at least one incident of serious cheating on written work. (McCabe, 2005).

This paper first examines reasons that college students cheat, using both the perspective of student respondents and the observations of the faculty authors. Next, the paper examines the two strategies which can be taken to combat student plagiarism: prevention and detection. Specific strategies are offered for each approach.

\section{WHY DO STUDENTS CHEAT?}

There is little cause to doubt that plagiarism is a widespread phenomenon on today's campuses Why do students cheat? The junior author on the article, herself an undergraduate university student, did an unofficial poll of 34 undergraduate students at a private university in a Southeastern State as to why people cheat on written assignments. Among the many reasons given, the top three were: the desire to get good grades, it's easier to cheat, and laziness. Although stated less frequently, the following "reasons" for cheating are probably representative of traditional aged students: desire to fit in with a certain group, feeling insecure about themselves, and to feel better about themselves. The author followed up on this questioning by asking 15 of the same students about the percentage 
of college students whom they feel cheat at some time in their college career. Answers ranged from 10\%-90\% with an average of $57 \%$.

One of the senior authors did a similar unscientific poll of her adult undergraduate students. The 31 respondents said that anywhere from $20 \%$ to $90 \%$ of students actually cheated with an average answer of $43 \%$. The top two reasons for cheating among this group of students were: laziness and it's easier to cheat. Tied for third place were the categories that students were too busy to do the work and the pressure to excel. The authors noted that the reasons for cheating did not vary much between the traditional 18-22 year olds and the adult student group, although the adults overall felt the percentage of cheaters was significantly lower. It could be argued that rather than reflecting more honesty among adults, this difference might reflect a more realistic appraisal of their peers by the undergraduate students, all of whom lived on campus in dorms and interacted with their fellow students more frequently.

Nor does it seem that plagiarism and cheating are phenomena confined to the United States. Another of the authors who teaches nursing students at the College of the Bahamas surveyed 38 of her students about their perceptions regarding cheating in college. When asked "What percentage of college students do you think cheat at some time during their studies?" this entirely female group answered from $20 \%$ to $90 \%$ with an average of $52 \%$. Their top three reasons "why college students cheat" were: laziness, fear of failure and not wanting to study. The reason of "basic dishonesty" was given frequently with one student saying that this dishonesty reflects the morals of society. One student said that students cheat "because they can."

Figure 1 summarizes the results of the convenience polls done with these three groups.

Figure 1: Summary Of Polls On Cheating

\begin{tabular}{|c|c|c|c|}
\hline Group & n & Estimated \% of cheaters & Top 3 reasons for cheating \\
\hline Nursing students & 38 & $57 \%$ & Laziness, fear of failure, not wanting to study \\
\hline Adult students & 31 & $43 \%$ & Laziness, easier to cheat, too busy/pressure to excel \\
\hline Traditional students & 34 & $52 \%$ & Desire to get good grades, easier to cheat, laziness \\
\hline
\end{tabular}

Three of the authors are professors of business at large private institutions in the Southeast and Midwest. The fourth author is a Lecturer at the College of the Bahamas where she teaches nursing students. Together they have many years of experience dealing with plagiarism. This experience suggests that the reasons for so much plagiarism can be broken down into at least five categories as shown in Figure 1.

Figure 1: Common Reasons for Plagiarism

\begin{tabular}{|c|}
\hline Ignorance \\
\hline Procrastination \\
\hline Papers for sale \\
\hline Cultural Acceptance \\
\hline Ease \\
\hline
\end{tabular}

The most common response when a student is accused of plagiarism is that what they did does not constitute plagiarism or that they simply were not clear on the definition of plagiarism. When confronted, these students will react with anger and indignation, often declaring that they just don't know what you are talking about. Many professors, the authors included, are suspicious that this reaction is just a ruse, but the insistence by students that they are being wrongfully accused at least opens up the possibility that true ignorance exists.

A second reason for widespread plagiarism is that students like many adults, procrastinate about doing their assignments and, when faced with impending deadlines, look for a quick solution. Many of the respondents in our polls cited laziness as the main reason for cheating. Laziness and procrastination may go hand in hand and we are considering them as the same phenomenon for purposes of this paper. Students who cheat because of procrastination 
will admit under pressure that they did know that what they were doing was wrong but that they had run out of time and were forced to take a shortcut. These students are often penitent, swearing they've never done this before and will never do it again, if you just give them a break.

Third, the current access to term papers on almost any subject is clearly a reason for growing plagiarism. Although few students will admit to buying term papers, the proliferation of online term paper mills suggests that the sale of term papers is a profitable business and that there clearly are customers available. Additionally, it is not uncommon to find ads in college newspapers that offer term papers and other assignments for a nominal fee. The sale of term papers has become a cottage industry in many college towns, as has the existence of ghostwriters who work their way through school by doing work for others who can't be bothered.

Fourth, there exists among college students today the idea that cheating is the norm and that in order to get ahead, one has to compete by any means possible, including plagiarizing. In some ways, students are simply mirroring the broader society where corporate scandals and questionable government ethics seem to point to a cultural norm of "doing whatever it takes" to advance one's agenda. Says Willen (2004):

In this climate what counts most are numbers and results, and those who get results, those who make the grade, regardless of how they go about doing it, reap the benefits. (para. 9)

Finally, plagiarism is just so easy that it is hard to resist. Temptation is everywhere. When the senior authors went to college, research was serious business. It required trips to the library, pulling out books, taking notes, Xeroxing materials, and laboriously constructing term papers. Today, in the college world of the junior author, research for faculty and students alike is facilitated by online, full-text resources from electronic libraries and websites like www.findarticles.com. Search engines take most of the time-consuming "searching" out of research and direct students to both academically sound and intentionally absurd websites on whatever subject they choose to research. Instead of taking notes, students cut and paste sections of these online sources, sometimes forgetting the need to later go back and paraphrase and source the materials, not to mention to organize the "pieces" into some type of coherent presentation.

Whether plagiarism is the result of one of these five categories or others, there are two main approaches to dealing with plagiarism. The first is a proactive strategy to preventing plagiarism from occurring in the first place. The second is a more traditional approach of detecting plagiarism and applying appropriate consequences. We start by examining strategies for prevention.

\section{STRATEGIES FOR PREVENTION}

In the ensuing discussion of strategies for prevention, each strategy will be directly related to one of the main reasons for plagiarism as shown in Figure 1.

\section{Fighting Ignorance}

The first step in assuring that the student who plagiarizes is not going to tell you that he or she did not know the rules is to stop assuming that students know what plagiarism is. Sure, it's easy to assure ourselves that faculty at the elementary and high school level should have already addressed these issues, but the reality is that many faculty members are not demanding that students document their sources. Often the sloppy scholarship habits of students have evolved before they get into college and may even be reinforced by college faculty who don't take the time or trouble to assure academic integrity. Thus students who plagiarize may just be continuing habits that have served them well for years and may be honestly bewildered when all of a sudden these habits and "research methods" are called into question. 
Says Film Studies Professor, Jill Craven:

What frightens me is that many of these students don't even recognize their theft of prose as something that is wrong. They show no remorse, just anger at being caught. (Johnson, 2000, para. 3) realized that:

When Professor Greene detected that some of his online students were lifting answers from web sources he

He had failed to advise students against turning in work that was not their own. Greene treated the incident as a teaching lesson for himself and has vowed to instruct students in detail about plagiarism and university policy on it in future courses. (Roach, 2001, para 5)

Each individual faculty member can help educate students regarding plagiarism by having strong statements regarding academic integrity in their syllabi. They can address these issues in class and give concrete examples of plagiarism. Further, they can refer students to websites which give concrete examples and guidelines for avoiding plagiarism and acknowledging sources correctly. A few such websites that the authors currently recommend to students are www.apastyle.org/elecsource.html, www.nec.edu/academics/library/InternetCiting.htm, and www. hamilton .edu /academics/resource/wc/usingsources.html.

At the institutional level, there should be a well publicized academic integrity policy which defines plagiarism and the organizational response to such activities. Often an Honor Court or equivalent is used to enforce the standards. In a recent study by McCabe, students at schools with honor codes reported far less cheating than did students at schools without honor codes. (2006)

\section{Dealing With Procrastination}

As reinforced by both our informal student poll and the observations of the senior authors, student procrastination is one of the key contributing factors to students deciding to plagiarize papers whose due dates are imminent. Faculty can proactively encourage students to work progressively on assignments by requiring outlines or sections of the paper to be turned in by interim dates. This ensures that students have started to work on the assignments and removes one of the key reasons for eventual plagiarism. It also gives the instructor the opportunity, if desired, to take a look at this work-in-progress and make note of any questionable areas with comments such as (1) Are your sure this is in your own words, (2) You need a reference note here, or (3) I don't see this source among your end references. Many instructors may not be willing to do this extra work, but the mere requiring of students to hand in outlines and sections is bound to help cure procrastination.

A paper needs to be treated as a process that requires continuous supervising and progress monitoring. Instructor's involvement minimizes a chance of a quick fix (e.g., buying or copying papers) since students need to demonstrate progress on an ongoing basis. (Born, 2003, para. 4)

\section{Countering Access To Papers For Sale}

When the authors recently did a quick online search for term papers for sale, Google produced links to 42,900,000 sites! These included sites such as essaytown.com, PerfectTermPapers.com, SameDayResearch.com and abcpapers.com which promises APA or MLA style papers on 15,000 topics and instant download. Of course, for a nominal fee, they will deliver a custom paper for you alone! The lure of these sites to students can be evidenced by the following blurb from one site that assures the students that buying term papers will help them meet their "academic potential."

In the past half decade our writing service has helped tens of thousands of college students in the U.S. and around the world. Our 24-hour service has met countless deadlines, written papers that seemed impossible and helped an infinite amount of students improve their GPA. Our goal is to help you succeed in all your academic endeavors and reach 
your potential. Let the experts take care of your writing needs and see what a difference we will make. (http://thepaperexperts.com/faq.shtml, para. 1)

While we are quite certain that students know about these sites, it astounds us that when talking to our faculty colleagues, many of them have very little awareness of what is commercially available to our students. The solution again starts with the faculty. Knowing what exists is the first step to devising a strategy to counter the problem.

One such strategy is to carefully craft your term paper requirements so that there is very little chance that the student will be able to find a previously written term paper on the subject. For example, take the example of a term paper for an undergraduate human resource management class. Instead of allowing a student to write a term paper on health care benefits in Corporate America, assign them to research their own company (if they are working) or the organization where their mother or father works in terms of the specific health benefits offered there and how it compares to what is being offered in other companies in the same industry. This type of assignment, while much more challenging, has many pedagogical benefits, not the least of which is that it is almost impossible to find a previously written term paper on the exact subject.

Another strategy is to require term papers with current references as many term papers for sale are full of dated references. Still another is to require students to hand in their sources along with the paper. Knowing they will have to do this may be enough to deter the wholesale purchase of a paper.

\section{Modifying Cultural Acceptance}

Faculty and administration are often shocked at the open admission by college students that they and their friends cheat. Reasons often center on staying competitive and the age-old excuse, "Everybody does it." Somewhat surprisingly, the blame for a culture of cheating is often put on the faculty and administration by the student body.

Many of the students I surveyed were troubled by the failure of their institution, and often its faculty, to address the issue of cheating. Because they believed that weak institutional policies and unobservant or unconcerned faculty were "allowing" others to cheat and, thereby, to gain an unfair advantage, students viewed cheating as a way to level the playing field. This was a particular problem on large campuses and in courses with large enrollmentsenvironments where, arguably, it is harder to establish a strong, positive community culture. (McCabe, 2006, para.5)

Individual faculty members need to talk about academic integrity with their students. Bring plagiarism out of the closet; demand high standards and hold everyone to those standards.

\section{Making It Harder To Cheat} any subject.

As stated above, advances in Internet access has made it exceedingly easy to piece together papers on almost

Most observers concede that plagiarism is not new but wonder really how widespread it has become. The temptation to cut and paste is undeniable; the vastness of the web and Internet gives an illusion of safety from detection. (Wagner, 2005, para. 4)

Several strategies have already been offered which would make this apparent ease less likely to suit the assignment. The authors also recommend that individual faculty members teach students how to properly reference papers. Don't assume they know and don't assert that it is someone else's job. A further recommendation is that faculty use plagiarism detection tools described below and tell students about these tools. Most students have no idea that their plagiarism can be detected fairly easily. Advertise the process and the consequences up front. Instead of trying to trap students who have plagiarized, try to educate students why they should not plagiarize.

Regardless of what prevention strategies you use, there is probably a need for a detection strategy as well. 


\section{STRATEGIES FOR DETECTION}

It is a well known principle of psychology that you get what is reinforced. The authors recommend that faculty make very transparent the system of detection and consequences for plagiarism. It has always been easy to become suspicious of plagiarism. Experienced faculty can spot differences in writing style, an academic prose that doesn't seem to fit the assignment, questionable references, and a string of references that don't appear in the end references, all of which are immediate cause of concern. Those familiar with the literature can also spot studies and references which the student has presented as his or her own. One of the authors even had the experience of an undergraduate student copying large sections of the author's own textbook without attribution.

In the latter case, proving the plagiarism was easy as the author knew just where to look. In other cases, faculty had to search laboriously for the articles which were plagiarized, sometimes asking the student to bring in all of his or her sources. In many cases, the proof was not forthcoming and the faculty member was obliged to give the student a grade that was probably undeserved.

The days when an academic could justifiably claim to have read all the books and journal articles written in their particular discipline have long gone with such expertise found in ever smaller areas of knowledge. (Goddard \& Rudzki, 2005, para 1)

Today, detecting plagiarism is much easier. Just as students have access to the Internet to copy and paste papers together, faculty have access to the Internet to detect this plagiarism. Two specific tools which are frequently used are Google and online plagiarism services like turnitin.com. Using a web-based search engine like Google to check for plagiarism consists of typing in suspicious-looking sentences from the student's paper and seeing if you find a match. (Born, 2003). McCullough and Homberg (2005) did an extensive study on using Google to detect plagiarism in master's theses, for example, and found word-for-word matches in $27.1 \%$ of the theses studied for just a 10 minute time period using Google.

Online plagiarism services, while more costly, are even more efficient and effective. Turnitin.com is probably the leader in the field and allows the professor to upload or cut and paste an entire paper. Within minutes, an originality report is returned which shows the word-for-word matches found with published articles, Internet sources, and other papers in their database. The color-coding enables the faculty member to immediately access the source and compare the two documents. While some of the matching may be standardized wording like the school's required headings and correctly quoted material, it is quickly apparent what degree of cheating has taken place. Better yet, the faculty member immediately has the proof needed to enforce consequences without fear of having a negative outcome in case of a grievance.

Turnitin, however, is not the only commercially available service to make it easier to detect plagiarism. Warger (2005) reports that Plagiarism-Finder is a software package available for $\$ 125$ while the Essay Verification Engine sells for only \$20. Warger further reports that the University of Virginia website offers Wcopyfind as a free program which searches for duplicated phrases in local files. The latter, however, is not able to search the web or Internet and so is considerably less comprehensive than a service like Turnitin.

\section{CONCLUSION}

Plagiarism abounds. Faculty members have a choice. They can continue to bemoan the rampant disregard for academic integrity and either punish those who plagiarize or save themselves work and aggravation by looking the other way. Or they can accept that plagiarism is a problem and that they are in a position to do something about it. Throughout history, it has been the deliberate acts of individuals that have made an impact on individual spheres of influence. Faculty may not be able to change the national plagiarism statistics by themselves, but in concert with other dedicated faculty, they can make an individual difference which, when taken in the aggregate, can make a difference. 
The authors suggest that plagiarism is everyone's responsibility and that educating students regarding academic integrity takes individual effort within a community of scholastic integrity. Students have the right to disregard academic standards if they see others doing so and getting away with it. A coherent, consistent policy regarding plagiarism, including instruction in the meaning of plagiarism, is in everyone's best interest.

\section{REFERENCES}

1. Bassinger, J. \& McCollum, K. (October 31, 1997). Boston U sues companies for selling term papers over the Internet. Chronicle of Higher Education, p. A34-35.

2. Born, A. D. (Fall, 2003). How to reduce plagiarism. Journal of Information Systems Education. Retrieved 1/28/06 from www.findarticles.com.

3. Frequently asked questions. Retrieved April 28, 2006 from http://thepaperexperts.com/faq.shtml.

4. Goddard, R. \& Rudzki, R. (2005) Using an electronic text-matching tool (Turnitin) to detect plagiarism in a New Zealand university. Journal of University Teaching and Learning Practice, 2(3b), 59-63. Retrieved 1/28/06 from http://jutlp.uow.edu.au/

5. Goode, S. (May 3, 1993). Trying to declaw the campus copycats - efforts to combat plagiarism by students and teachers on college campuses. Insights on the News. retrieved 1/28/06 from www.findarticles.com.

6. Johnson, H. P. (May/June 2000). Confronting plagiarism. Academe. Retrieved 1/28/06 from www.findarticles.com.

7. McCabe, D. L. (Summer/Fall, 2005). It takes a village: Academic dishonesty \& educational opportunity. Liberal Education, retrieved 1/28/06 from www.findarticles.com.

8. McCullough, M. \& Homberg, M. (Sept. 2005). Using the Google search engine to detect word-for-word plagiarism in master's theses: A preliminary study. Retrieved 1/28/06 from www.findarticles.com.

9. Roach, R. (June, 2001). Safeguarding against online cheating — distance education standards and plagiarism. Black Issues in Higher Education. Retrieved 1/19/06 from www.findarticles.com.

10. Scanlon, P. M. (May/June 2002). Internet plagiarism among college students. Journal of College Student Development. Retrieved 1/28/06 from www.findarticles.com.

11. Sterngold, A. (May/June, 2004). Confronting plagiarism: How conventional teaching invites cybercheating. Change. Retrieved 1/28/06 from www.findarticles.com.

12. Warger, T. (October 2005). Catching copy cats: With the wide number of anti-plagiarism tools available today, students looking to lift others' work don't stand much of a chance. University Business. Retrieved 1/19/06 from www.findarticles.com.

13. Willen, M. S. (Fall 2004). Reflections on the cultural climate of plagiarism. Liberal Education. Retrieved 1/19/06 from www.findarticles.com. 


\section{NOTES}

